\title{
Understanding the Roles of Effectuation and Bricolage in the Opportunity Creation Framework
}

\author{
Samuel Chinyoka ${ }^{1}$ \\ ${ }^{1}$ Department of Management, University of Botswana, Botswana \\ Correspondence: Prof Samuel Chinyoka, Department of Management, University of Botswana, Botswana. \\ E-mail: chinyoka@ub.ac.bw
}

Received: November 15, 2019

Accepted: December 6, 2019

Online Published: February 3, 2020

doi:10.20849/abr.v5i1.707

URL: https://doi.org/10.20849/abr.v5i1.707

\begin{abstract}
The process of entrepreneurship is identifying and exploiting opportunities. Entrepreneurial action can also result in forming, rather than merely encountering opportunities. Researchers, like Alvarez and Barney (2007), also distinguish two approaches to entrepreneurial action, discovery and creation. In opportunity creation, opportunities for entrepreneurial profit are formed endogenously through action.

Effectuation processes focus on what can be done, given the capacity to influence and means at hand, to move toward a future endpoint. Effectuation was developed in the context of entrepreneurship and it assumes that an opportunity may arise through control-based strategies.

Bricolage was initially described by Levi-Strauss (1967) as 'making do with what's on hand'. This was extended by Baker and Nelson (2005) and applied to the process of value creation. They observed that some entrepreneurs prefer to engage in a process of "making do by applying combinations of resources at hand to new problems and opportunities".

These are new concepts to most entrepreneurship researchers, yet extremely useful in the understanding of opportunity creation. This conceptual paper will assist in the understanding of these concepts, and clarify the roles of effectuation and bricolage in the opportunity creation framework. A discussion section should attempt to bring the concepts to reality by highlighting realistic examples.
\end{abstract}

Keywords: effectuation, bricolage, opportunity, entrepreneurship, resources

\section{Introduction}

The purpose of this conceptual paper is to contribute to cutting edge debate in entrepreneurship. Current debate in entrepreneurship revolves around innovation in high-tech enterprises, new product development, business model innovation, and similar areas. These are areas where participants face uncertainty and risk. New constructs and theories are being defined. At the cutting edge are constructs like effectuation, bricolage and opportunity creation.

It is necessary for researchers in the field of entrepreneurship to be familiar with these terms and their principles, because, perhaps for the first time, entrepreneurship enters its own independent and non-eclectic phase. It is an opportunity that should not be missed by researchers, as taking it up could enable us to play a meaningful role in the promotion of the new, technological-type enterprises.

The paper initially defines and discusses the three themes: effectuation, bricolage and opportunity creation. Next, common threads of the themes will be highlighted, showing pertinent relationships among them. Possible areas of application of the themes will briefly be discussed, followed by a general discussion. Conclusions and recommendations for future research will round-off the paper.

\section{Context}

As we enter the 21st Century, most African and developing countries face opportunities in young and growing populations, ballooning populations of educated youths, and amazing in-exhaustible, fast growing technological opportunities. However, these opportunities fail to yield any tangible benefits as the majority of the graduating youths find themselves walking the streets of the growing shanties and towns. As if this is normal, most of the 
governments' demeanour continues to match the previous century one, where progress was taken for granted, with little initiative from the local rulers.

For most African rulers, success is seen from an individualistic perspective, rather than the national perspective "If I be elected and become a Minister, then I will have the opportunity for personal accumulation". Progressive Governments in Europe and the east concentrate on leadership in the area of innovation since they realize that this is the way to benefit their populations. Many of the African Governments do not even realize that the world is now tackling the fourth revolution - they are still wallowing at the first stages of the Industrial Revolution.

Countries in the East, China, Singapore, Malaysia, and lately India, Dubai, etc. seem to have managed to progress over generations of technology and have caught up with the Western Nations. Their Research and Innovation Agendas, now talk to those of the more developed Western Nations. They have managed to do this in a matter of decades. This demonstrates how serious their governments have been.

When we come to the research dialogue in entrepreneurship, we can now clearly see that the agenda being pursued by these eastern countries is significantly different from that agenda still being pursued by African researchers. We continue asking mundane research questions in line with mundane projects taken up by our entrepreneurs. Researchers in the east deal with high-tech entrepreneurs, because the majority of start-ups in Asia are high-tech. In Africa, it is very difficult to find high-tech start-ups, even from engineering graduates. This, to an extent, dictates the research agenda. A number of questions need to be answered in the African context: who is responsible for the determination of the country's range of start-up projects? Do Governments' Development Plans endeavour to determine this range of projects? How can they be made to do so? Does the system of education determine the kind of start-ups young people come up with? What is the difference in this education between these two global regions? We need to find the underlying causes of the separation of Asia and Africa in terms of the development agenda. It is clear that, following the different development agendas, Asian start-ups seem to be more high-tech than African start-ups. Hence, in their entrepreneurship research agendas, the Asians are asking different research questions since most of their start-ups are facing uncertainty while, perhaps those in Africa are still dealing with the simpler types of risk.

\section{Problem Statement}

African researchers have been left behind. In entrepreneurship research, the frontiers are further away from us than other researchers in the global fraternity. We need to keep up in terms of constructs and theories we use.

This problem emanates from the structural problems discussed above. Solutions to such problems may lie mainly in other spheres, but as researchers, we can contribute by pointing them out and suggesting ways to solve them.

An issue that affects University researchers is the kind of education we continue to participate in. Insightful ordinary people have started questioning us whether we are convinced that ours is a positive contribution. A lot of us have started to defend the status quo. We have come up with theories like Human Capital Theory (Becker, 1962) that absolve Universities from taking responsibility for producing unemployed graduates. We state that our task is to educate; the employer must train. Yet the issue might be deeper than that. Are our graduates trainable?

Universities seem to engage in some empty competition to produce numbers. The more numbers we produce, the more we get financial support; and the shallower our graduates become. Recently, Universities have embarked on entrepreneurship and significant numbers of graduates are coming off stream. The performance of these graduates has also been dismal. They can neither create the jobs nor can they employ themselves. Surely, we need to go back to the cross-roads! We have been following the process of causation for too long instead of choosing effectuation. In order change course, we need to understand the new course we have to take, hence the need to clarify concepts like effectuation, causation, bricolage, and opportunity creation.

\section{Purpose of the Article}

The main purpose of this article is to introduce three concepts that are relatively new in entrepreneurship literature. These concepts are variously referred to as 'themes', 'processes', or 'constructs'. While they are many such new concepts, of interest are effectuation, opportunity creation and bricolage. These concepts will be defined and clarified, and pertinent examples will be given, including pertinent examples in Botswana. Any relationships among them will also be explained.

Start-ups are important in African countries since the more they are, the faster the rate of development. Africa also needs to start thinking about the quality of start-ups, not only the quantity of start-ups. Quality of start-ups relates to the sophistication of the activity being started up. The fast growing of the less developed countries, like China, India, Viet Nam, etc., now promote start-ups at the higher end of the technological scale. If African 
countries are to catch up, they need to operate at that level. A lot of uncertainty exists at that level, which necessitates concepts like effectuation.

\section{Theoretical Framework}

Sarasvathy (2001a) contrasted causal approaches to developing business from effectual approaches. "Causal rationality starts with a predetermined goal and a given set of means, and seeks to identify the optimal, such as fastest, cheapest, or most efficient alternative to achieve the given goal" (Heikkila and Heikkila, 2017:201). The effectuation process is more subjective, and starts with available resources and capabilities of the entrepreneur, then takes this "set of means as given and focus on selecting between possible effects that can be created with that set of means" (Sarasvathy, 2001a).

Managerial Thinking - Causal Reasoning

Distinguishing Characteristics:

Selecting between given means to achieve a pre-determined goal.

\section{Entrepreneurial Thinking - Effectual Reasoning}

\section{Distinguishing Characteristics:}

imagining possible new ends using a given set of means.
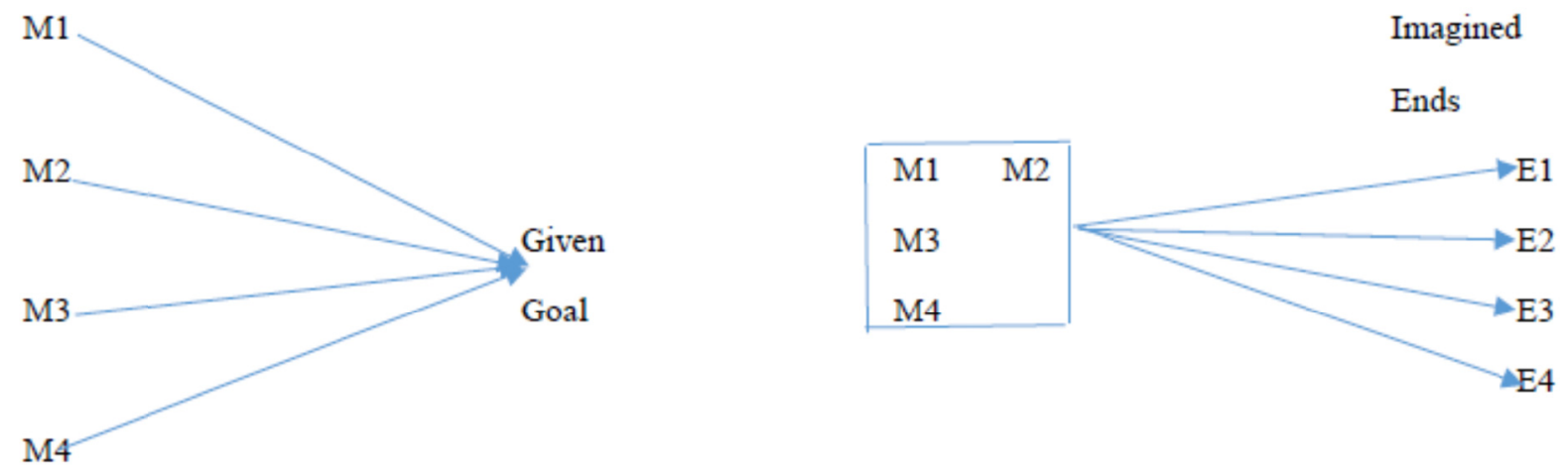

Figure 1. Causal and effective reasoning (Sarasvathy, 2001a)

\section{Effectuation}

Sarasvathy (2001b:244) defines an effect as "the operationalization of an abstract human aspiration". Effectuation basically tries to do just that.

Fisher (2012) defined effectuation as a mode of entrepreneurial behaviour under conditions of uncertainty. Sarasvathy (2001b) brought a different dimension to effectuation by stating that actors can create a variety of effects when they attempt to exert influence over things they can control. In other words, effectuation processes do not set a specified end point, but focus on what can be done, given resources at hand, to move toward a yet-to-be-determined near-term future end point. To determine the means through which the actor can exert control over the world, he/she has to first ask who they are, what they know and whom they know (Sarasvathy, 2001b). The diagrams above provide the distinguishing characteristics of causation and effectuation - "choosing between means to create a particular effect" (causation) versus "choosing between many possible effects using a particular set of means" (effectuation).

A crude example can be given which relates to our kind of education: if one of us is asked to come up with a curriculum, what do we normally do?: google existing curricula across the world, pick the best or what we believe to be a combination of the best. We are even required to demonstrate sufficient benchmarking. We are definitely choosing between different means to create a particular effect. If we can think outside the box, we need to come up with many possible curricula using our own creativity and then choosing what is best for our situation. Possible curricula could emanate through discussion with employers or industry leaders who know gaps in the market that could be filled by new entrepreneurs, not established Harvard or University of Cape Town curricula.

Another example can be found in the area of research. One can say causation is akin to deductive reasoning where you start off with a definite ending in mind, disproving an already known theory (pre-specified). Sure, one can choose between means to do that. On the contrary, effectuation would be akin to inductive reasoning where 
you use a particular set of means to generate a choice effect from among many possible effects. The technique of allowing issues to unfold can give more meaning to effectuation as it allows contingencies to be built in.

From the questions used to determine means through which the actor can exert control, Effectuation Theory has been developed which suggests two ways of understanding effectuation: as a mode of behaviour; and as a sequence of activities with different starting and end points (Sarasvathy, 2001b; Fisher, 2012). As a mode of entrepreneurial behaviour, Effectuation Theory converges on four principles:

a) Affordable loss rather than expected return;

b) Strategic alliances rather than competitive analysis;

c) Exploitation of contingencies rather than exploitation of pre-existing knowledge; and

d) Controlling an unpredictable future rather than predicting an uncertain one (Sarasvathy, 2001b, p 252).

There are three assumptions about the opportunity, context and actor in effectuation:

1. Effectuation assumes that an opportunity may arise via the control-based strategies.

2. For context, effectuation was developed through entrepreneurship-related think-aloud experiments with expert entrepreneurs (Sarasvathy, 2001b; 2008).

3. Effectuation does not address the motivations of entrepreneurial actors directly, but the means-based principle includes answers to the question, who am I? The actor in effectuation influences his/her environment through his/her means and iterates based on the response from the environment.

From a process perspective or as sequences of activities, Effectuation Theory introduces an 'episode' concept defined as the sequence of events. These processes are not homogeneous across episodes, but differ in terms of five process characteristics:

a) Perception of uncertainty;

b) Nature of aspirations;

c) Information processing;

d) Orientation of new goals; and

e) Attention to new goals.

These characteristics also led to two overall types of effectuation processes: Externally- motivated Effectuation (Type 1) and Internally-motivated Effectuation (Type 2) (Jiang and Ruling, 2019).

To further explain some of the concepts above, Jiang and Ruling (2019) state that "affordable loss" means that the entrepreneur will only take up downside risks they can handle, those that cannot be handled are avoided. In "strategic alliances", entrepreneurs acting in the effectuation mode tend more strongly towards negotiating pre-commitments and creating alliances with stakeholders; while with "exploitation of contingencies", entrepreneurs acting in the effectuation mode seek to exploit unexpected events and opportunities. Entrepreneurs acting in effectuation mode control an unpredictable future through control of uncertainty by taking a set of means as given and seeking to create outcomes that are possible with their set of means.

\section{Bricolage}

Effectuation and bricolage are closely related (Fisher, 2012). Bricolage is applied to people with a good understanding of resources at hand, innovative, good use of a combination of resources at hand to solve problems or pursue opportunities, and an active self-correcting trial-and- error "make-do" behaviour. Entrepreneurs that are passionate about developing their firms and inventing new solutions are more likely to engage in bricolage (Stenholm and Renko, 2016). Further, bricolage is a form of effectual reasoning of an entrepreneur to avoid risks firms experience during their critical early years (Stenholm and Renko, 2016). Effectuation can be seen as an innovation driver, while bricolage is seen as one of the innovating methods (Christensen, 2009).

The originator of the term 'bricolage', Levi-Strauss (1967), initially described two types of bricolage: ideational bricolage and material bricolage. Ideational bricolage describes the process of recombining earlier myths to create new myths serving new functions; whereas material bricolage represents the combination of resources at hand to find novel and workable approaches to overcome problems and exploit opportunities (Baker and Nelson, 2005). Rather than focusing on activities that give them an advantaged resource position, as perspective on entrepreneurial action infused by strategy and organizational theory suggest, or acting in ways to shape near-term reality as the logic of effectuation suggests, bricoleurs engage in a different activity entirely. They use 
resources on hand to solve the problem in a new way, or combine existing resources to potentially unlock a new source of value.

Hence, while both effectuation and bricolage might operate in situations of some uncertainty, effectuation aims at shaping an unspecified near-term future, while bricolage aims at solving either a known or unknown problem. Both effectuation and bricolage seem to apply in a world of formed opportunities, rather than encountered opportunities. Bricolage represents a form of value creation that does not depend on the Schumpeterian assumption that assets are withdrawn from one activity for application in another (Baker and Nelson, 2005:362). Hence, bricoleurs often draw from unrelated or undeveloped resources during the opportunity-creation process. Baker (2007:705) clarifies an act of bricolage this way: "simply seeking out or paying discount prices does not, of course, constitute bricolage. But making use of a resource because it is available cheaply or for free, rather than because it is the 'right' resource, and then combining it with other resources to take advantage of some new opportunity exemplifies bricolage". Hence, the measure of bricolage depends not on the cost of the item, but on its comparison to the 'right' resource and its use. Using the resource for its intended purpose does not constitute bricolage.

In our crude examples above, a bricoleur working on a curriculum would 'draw from unrelated or undeveloped resources' (their conception of need in the real world and non-academic sources on the ground). We should note that these resources are available cheaply, they are not obviously the 'right' resources, but can be combined with other resources to take advantage of new opportunities. In the research example, a bricoleur is typified by a qualitative researcher going into the field with one or two general focus research questions (not a detailed structured questionnaire) and use the creativity and knowledge of research subjects to create new theories. The concept of ideational bricolage, where earlier myths are combined to come up with new myths applies here, even though it might be necessary to explore the concept further.

\section{Opportunity Creation}

Shane (2003) asks: Why do some people and not others discover opportunities? And, why do some people and not others act to exploit them?

Two approaches to entrepreneurial action are presented: discovery and creation. Under 'discovery', the product or factor market imperfection is taken as given, since the mechanism that generates the imperfection is exogenous to the process. It is the imperfection that presents the opportunity. Under 'creation', it is how the market imperfection is generated, and the mechanism, human action, is endogenous to the process (Alvarez and Barnes, 2007; Wood and McKinley, 2010).

Three assumptions are discussed concerning opportunity, context and actor in opportunity creation:

1. In opportunity creation, opportunities for entrepreneurial profit are formed endogenously through action. Hence, opportunities cannot exist apart from the actions that form them, and the human social institutions requiring human action for their generation and social agreement for their persistence (Alvarez, Barney, McBride and Wuebker, 2014).

2. The decision-making context in opportunity creation is that of either Knightian uncertainty, where outcomes or probabilities cannot be estimated ex-ante, or Knightian risk where they can be estimated ex-ante.

3. The role of the actor in opportunity formation is a necessary condition for opportunity formation, yet there are few explicit assumptions about their cognitive or behavioural aspects.

Related to opportunity creation is opportunity shaping. Opportunity shaping is the process to transform and connect internal and external resources for opportunity creation (Abdelgawad, Zahra, Svejenova and Sapienza, 2013). Effectuation enables new firms to shape opportunities (opportunity shaping) with different ways of resource combinations, such as reconfiguring and transposing through a series of strategic experiments (Guo, Cai, and Zhang, 2016). Hence, effectuation has a positive effect on opportunity shaping, which in turn affects opportunity creation. This implies a positive relationship between effectuation and opportunity creation.

Prior research has suggested that both reconfiguring and transposing (opportunity shaping) involve some degree of bricolaging, or the recombining of resources at hand in creative ways to address emerging opportunities (Abdelgawad et al., 2013). Hence, if effectuation has a positive effect on opportunity shaping and opportunity creation, it should have a positive effect on bricolage. 
If in the above crude examples, the curriculum developer and the researcher can use effectuation to generate those imagined ends, they can better succeed as effectuation enables them to mobilize both opportunity creation and bricolage.

\section{Conceptual Overlaps for Opportunity Creation, Effectuation and Bricolage}

The three frameworks' universe is value creation, or they speak to value creation although they do not represent all forms of value creation. Some forms of value creation that are not included are causation and opportunity discovery. The diagram below depicts the overlaps, which explain their relationships.

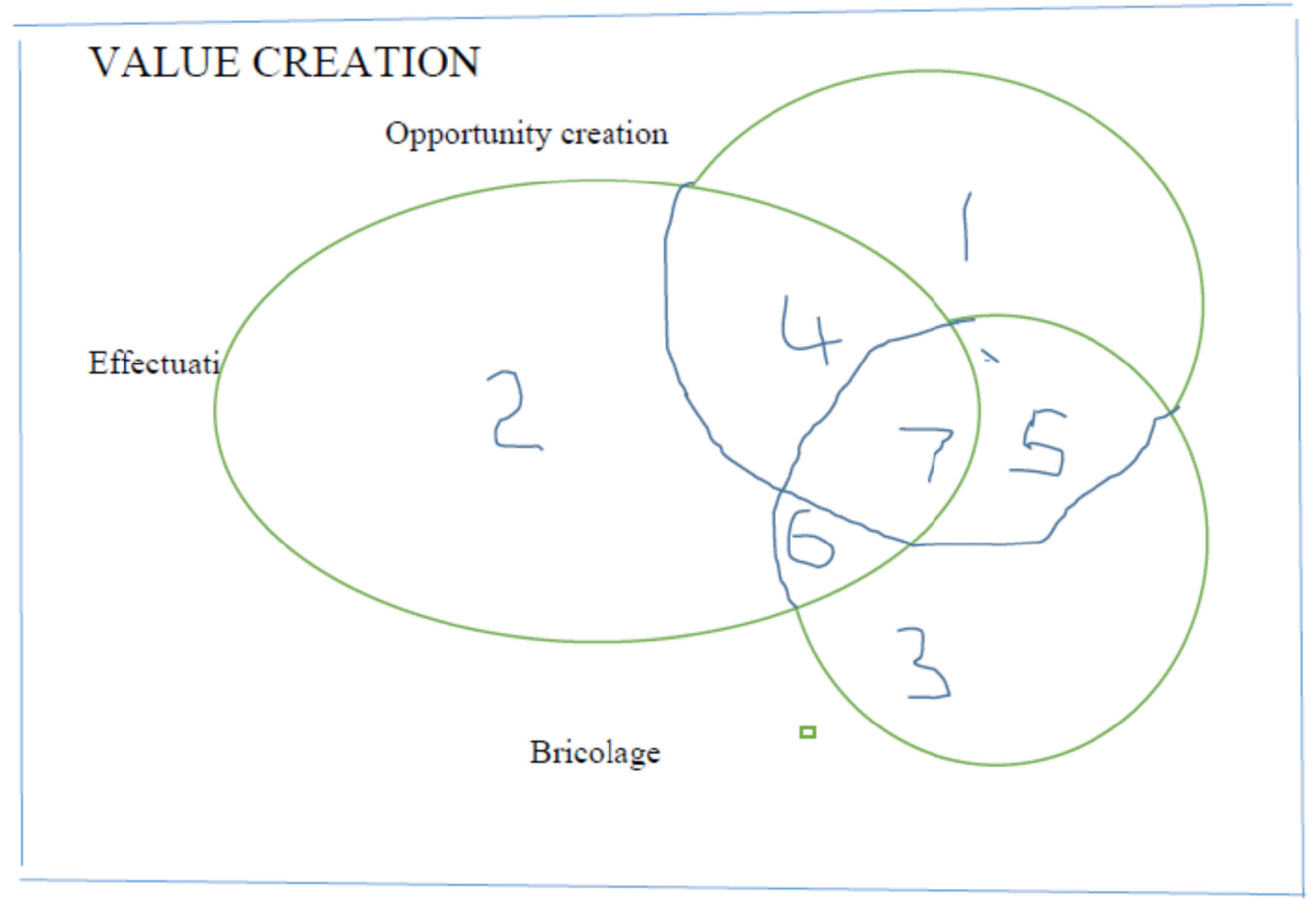

Source: Welter, Mauer and Wuebker, 2016

Area 1: This represents opportunity creation without bricolage and effectuation. Hence, there are many different ways to form the competitive imperfection. Opportunity creation can be considered under other behavioural models.

Area 2: This represents effectuation in the absence of opportunity creation and bricolage. This demonstrates that effectuation may apply to fields beyond entrepreneurship (Sarasvathy, 2001b). The heuristics of effectuation maybe applied to non-business decisions, like making dinner, which is outside the bounds of opportunity creation and would not require bricolage. Strictly speaking our two crude examples above might fall into this category.

Area 3: This area represents bricolage without effectuation and opportunity creation. In many situations, bricolage may not be directed toward the formation of an opportunity or rely on heuristics of effectuation.

Area 4: This represents the overlap between effectuation and opportunity creation that excludes bricolage. (1) An entrepreneur may have the means on hand that are put to their typical use, thus not involving bricolage. (2) An entrepreneur may be independently wealthy and, thus, able to finance all the appropriate required resources.

Area 5: This refers to situations that involve both opportunity creation and bricolage and it excludes effectuation. This represents aspects of opportunity creation such as human resources drawn from the entrepreneur's social network, that involve making do with what's on hand in novel ways (Banerjee and Campbell, 2009). 
Area 6: This shows effectuation and bricolage coinciding in the absence of opportunity creation. It may represent situations outside the economic sphere in which effectuation is applied and informed by bricolage. Effectuation has a characteristic of serving a particular function and evolving to serve another. The saying "turning swords into plough shares" demonstrates this characteristic of effectuation, where a tool was primarily made for something, but can be co-opted for something else. This also represents 'evolutionary' bricolage.

Area 7: This represents the overlap of all three of the concepts. These are situations in which an effectual decision model requires the making do with what's on hand in novel ways, while pursuing the creation of a market impaction. Sarasvathy (2001b) used the example of the company U-Haul, which used customers as sales people to rapidly gain a nation-wide network. This is quite common with Network Marketing Companies. The use of customers, who are not typically sales people, but an available resource, represents bricolage. Using principles of effectuation, customers became committed stakeholders that created the opportunity. In Network Marketing, customers are seen as independent business people who create large pools of permanent consumers.

In African economies, including that of Botswana, the street vendors depend greatly on strategic alliances, where a fellow street vendor's business can be pushed by fellow vendors in their absence. When a so-called vendor's customer comes in the absence of the vendor, those present, even though they trade in the same wares, will not 'take' the customer but transact business on behalf of their fellow vendor who might be sick or doing some other chores like purchasing, and keep the proceeds for him/her. They know that the same will happen in their absence. Competition is at some different level.

\section{Discussion}

To achieve the impossible, one has to see the invisible. That is how effectuation can be defined and separated from causation. What is currently considered as logical and normal in this era is the process of causation. Unfortunately, our economic and management theories are based on causation. Even where entrepreneurs and innovators are trained, they are first grounded in the principles of causation which is seen as objective and logical. Unfortunately, this approach seems to create conservative entrepreneurs, who, although accepting some level of risk, strive to minimize risk. In doing so, they also minimize the number of ends to only one goal in this scenario.

This paper's main interest is the situation where the three concepts overlap since this is where the relationships can be clarified. A Mr Jia Jiang, founder of Fearbuster.com, wrote a book titled Rejection Proof published in 2015. He always had a dream to be in business and when he got employed by one of the large companies after graduating with Computer Science and an MBA, he exceedingly got frustrated. His wife urged him to leave his job and pursue his dream, and his project was to establish an app. He did all that could be done including hiring experts to design the app. When he approached possible financiers, he was turned down flat. He found out that he could not take a no as it hurt him so much that he even feared to pursue other possible financiers. Instead of pursuing the project, Mr Jia Jiang decided to confront his fear of rejection by going through 100 days of requests (most of which could be seen as ridiculous) to various people he could identify. The objective was for him to be rejected by all, which to his reasoning would strengthen him to be rejection-proof. Some of these requests generated responses that put him on the news. At the end of the 100 days, Mr Jia Jiang abandoned the initial project of establishing the app since he was now fully involve in a 'new' industry, that of fear-bustering.

Mr Jia Jiang demonstrates what we can term a transition from causation to a decision model that combines effectuation and bricolage while creating something that would impact the market even though it was not his intention, in the first place. In his attempt to create an app, we note that even though this could be classified as causation, he had very little resources that he had to make do in novels ways by hiring students to work on a part-time basis developing his app. His idea was that, once the app was developed, it would attract funders. It could have attracted funders if $\mathrm{Mr}$ Jia was patient enough and was able to take rejections and still continued to seek help. He failed to persist in this direction since he just could not take rejection at this time, hence his decision to strengthen his resistance. In the process of doing this, the American public learnt something about him, showed some appreciation, diverting him completely from his initial path of causation.

Mr Jia took a difficult decision, something akin to impossible, when he decided on 100 days of rejection. In effectuation, the means initially available to a person is virtually themselves. This is why they have to ask the three questions: Who am I? What do I know? And whom do I know? Mr Jia seemed to be lacking in all three areas - he did not know much about himself, he only discovered too late that he could not take rejection, he had no technical experience although he knew where to get it from; and he did not seem to know many possible financiers. He had to work on these, hence he shelved his initial project. In the process of working on them, however, Mr Jia came across a set of means that led him to a number of possible effects, and the effect he finally 
selected is not the original one. Seeking rejection was a difficult project and it was emotionally painful. Yet he utilized simple and free resources and the effect was unexpected. He combined effectuation and bricolage to create an unexpected opportunity.

If our entrepreneurs are to succeed in operating in both effectuation and bricolage modes to achieve the creation of opportunities, they have to accept uncertainty. The kind of projects that will place us into the correct development path involve a lot of uncertainty. New technology projects are of that nature. Secondly, the entrepreneurs need to be clear and convinced on their initial three means - who they are: or are they capable to do what it takes; secondly, what they know: or do they have what it takes; and thirdly, whom they know: or have they built sufficient networks.

\section{Conclusion and Recommendation}

The paper aimed to relate effectuation and bricolage in the opportunity creation framework. We have demonstrated that effectuation directly affects bricolage on the one hand, and opportunity creation through opportunity shaping. An effectuator aims at affordable loss rather than expected return. Strategic alliances are more important for the effectuator than competition. He/she exploits contingencies in the process of controlling an unexpected future. Bricolage, which is a form of effectuation, can occur when the individual understands resources at hand in order to make do. An entrepreneur in the effectuation mode finds it easier to be a bricoleur. Opportunity creation results from endogenous action taken by the entrepreneur. It is affected by the levels of both effectuation and bricolage.

A number of realist, though crude examples (or mini-case studies) have been outlined to demonstrate the three constructs. From entrepreneur literature, it seems that both entrepreneurs and entrepreneurship researchers in the Eastern countries are better at mastering effectuation, and bricolage, hence improving their opportunity creation better than their African counterparts. Effectuation teaches us to ask three questions about ourselves: who we are, what we know, and whom we know. These will not only enable us to effectuate, but to bricolage as well in the process of opportunity creation.

Both researchers and entrepreneurs in Africa need to learn from these concepts in order to stretch themselves to the level of global competitors. While it is possible to use each of the three concepts separately, or indeed in pairs, entrepreneurs are more effective innovators if they can combine the three - effectuation, bricolage and opportunity creation - in their innovative pursuits.

This is not easy for most African entrepreneurs, in our view. Effectuation has not yet developed as a common culture as most of us grow up under the causation culture. A paradigm shift is therefore required to change to effectuation. Secondly, our 'entrepreneurs' are not innovative, and where bricolage is a form of innovation, they easily give up when traditional resources are not forthcoming. Thirdly, they are still in the era of opportunity discovery as opposed to opportunity creation.

If it is that difficult for our 'entrepreneurs' to take each of the three concepts separately, achieving all of them together is an impossible dream. We need to actively sensitize our entrepreneurs to such concepts, even training them in their approaches.

\section{References}

Abdelgawad, S. G., Zahra, S. A., Svejenova, S., \& Sapienza, H. J. (2013). Strategic leadership and entrepreneurship capability for game change. Journal of Leadership \& Organizational Studies, 20(4), 394-407.

Alvarez, S. A., \& Barney, J. B. (2007). Discovery and creation: alternative theories of entrepreneurial action. Strategic Entrepreneurship Journal, 1(1/2), 11-26.

Alvarez, S. A., Barney, J. B., McBride, R., \& Wuebker, R. (2014). Realism in the study of entrepreneurship. Academy of Management Review, 39(2), 227-231.

Baker, T. (2007). Resources in play: bricolage in the toy store(y). Journal of Business Venturing, 22, 694-711.

Baker, T., \& Nelson, R. (2005). Creating something from nothing: resource construction through entrepreneurial bricolage. Administrative Science Quarterly, 50, 329-306.

Banerjee, P. M., \& Campbell, B. A. (2009). Inventor bricolage and firm technology research and development. $R \& D$ Management, 39(5), 473-487.

Becker, G. S. (1962, Oct.). Investment in human capital: A theoretical analysis. Journal Economy, 70(5), part 2, 9-49. 
Fisher, G. (2012). Effectuation, causation and bricolage: a behavioural comparison of emerging theories in entrepreneurship research. Entrepreneurship Theory and Practice, 36(5), 1019-1051.

Guo, R., Cai, L., \& Zhang, W. (2016). Effectuation and causation in new internet venture growth: the mediating effect of resource bundling strategy. Internet Research, 26(2), 460-483.

Heikkila, J., \& Heikkila, M. (2017). Innovation in micro, small and medium size enterprises: New product development, business model innovation and effectuation. AIS Electronic Library (AISeL), BLED 2017 Proceedings, pp. 197-211.

Jia, J. (2015). Rejection Proof. Harmony Books, N. Y.

Jiang, Y., \& Ruling, C. C. (2019). Opening the black box of effectuation processes: characteristics and dominant types. Entrepreneurship Theory and Practice. Retrieved from journals.sagepub.com

Levi-Strauss, C. (1967). The Savage Mind. Chicago: university of Chicago Press.

Sarasvathy, S. D. (2001a). What makes entrepreneurs entrepreneurial?. pp.1-9. SSRN. Retrieved from https://ssrn.com/abstract=909038https://ssrn.com/abstract $=909038$

Sarasvathy, S. D. (2001b, April). Causation and effectuation: Towards a theoretical shift from economic inevitability to entrepreneurial contingency. The Academy of Management Review, 26(2), 243-263.

Sarasvathy, S. D. (2008). Effectuation: Elements of Entrepreneurial Expertise. Edward Elgar: Cheltenham, U. K.

Shane, S. (2003). A General Theory of Entrepreneurship: The Individual-Opportunity Nexus. Edward Elgar: Northampton, U. K.

Stenholm, P., \& Renko, M. (2016). Passionate bricoleurs and new venture survival. Journal of Business Venturing, 31(5), 595-611.

Welter, C., Mauer, R., \& Wuebker, R. J. (2016). Bridging behavioural models and theoretical concepts: effectuation and bricolage in the opportunity creation framework, Strategic Entrepreneurship Journal, 10(1), 5-20.

Wood, M. S., \& McKinley, W. (2010). The production of entrepreneurial opportunity: a constructivist perspective. Strategic Entrepreneurship Journal, 4(1), 66-84.

\section{Copyrights}

Copyright for this article is retained by the author(s), with first publication rights granted to the journal.

This is an open-access article distributed under the terms and conditions of the Creative Commons Attribution license (http://creativecommons.org/licenses/by/4.0/). 